\title{
You Are a Document Too: Web Mining and IR for Next-Generation Information Literacy
}

\author{
Bettina Berendt \\ Department of Computer Science, K.U. Leuven, B-3001 Heverlee, Belgium \\ http://www.cs.kuleuven.be/ berendt
}

Information retrieval and data mining often assume a simple world: There are people with information needs who search - and find - information in sources such as documents or databases. Hence, the user-oriented goals are (a) information literacy: the users' ability to locate, evaluate, and use effectively the needed information, and (b) tools that obviate the need for some of the technical parts of this information literacy. Examples of such tools are search-engine interfaces that direct each user's attention to only an individualised part of the "information overload" universe.

In this talk, I will argue that such simple-world assumptions are no longer justified, advocate a shift in focus, and outline concrete steps for using technology to further a more comprehensive form of information literacy. I will focus on data, documents, and information-related activities on the Web, which are analysed in Web mining and (Web) IR:

1. In today's (Web) information society,

- the problem is not just information overload, but also information sparsity

- information-related activities involve disclosing and withholding (the latter known under names such as "privacy" or "business secrets")

- each information-related activity has (at least) one source, one manifestation as data/document, one user and one stakeholder; network effects abound.

- most importantly, the dichotomy of information-seeking users and information-containing data/documents has vanished in a time when virtually every activity generates data/documents.

2. These considerations lead to a new operationalisation of information literacy, understood in its broader sense as a set of competencies that a citizen of an information society ought to possess to participate intelligently and actively in that society.

3. Based on a range of concrete examples, I will illustrate how tools can support this type of information literacy (and obviate the need to know some technical details). 